\title{
Explaining patterns of species dominance in the shrub steppe systems of the Junggar Basin (China) and Great Basin (USA)
}

\author{
Wendy TROWBRIDGE ${ }^{1 *}$, Thomas ALBRIGHT², Scot FERGUSON ${ }^{1}$, Jun LI $^{3}$, Barry PERRYMAN ${ }^{4}$, Robert \\ S NOWAK ${ }^{1}$ \\ ${ }^{1}$ Department of Natural Resources \& Environmental Science, University of Nevada Reno, Reno NV 89557, USA; \\ ${ }^{2}$ Department of Geography, University of Nevada Reno, Reno NV 89557, USA; \\ ${ }^{3}$ Xinjiang Institute of Ecology and Geography, Chinese Academy of Sciences, Urumqi 830011, China; \\ ${ }^{4}$ Department of Agriculture, Nutrition and Veterinary Sciences, 1664 N Virginia Street, Mail Stop 202, University of Nevada Reno, \\ Reno NV 89557, USA
}

\begin{abstract}
Natural scientists have long recognized that regions with similar climate tend to have similar vegetation. Preliminary observations suggest that shrub steppe communities of the western US and western China may be two such regions with similar annual precipitation, temperature, land use, and vegetation. These cold dry shrub steppes have traditionally been grazed. Despite these similarities, patterns of species dominance are different. Annual species that are rare in China become dominant when introduced to the United States. The objective of this study was to investigate how climate, land use and community structure may explain these patterns of species dominance. Community structure and grazing intensity were measured at 5 sites in each region. This information was combined with a broader review of the literature describing the history of grazing in both basins. Climate was analyzed based on a spatially-gridded, interpolated weather time series (monthly records) and climatological summary (1961-1990 mean conditions) data set from the Climate Research Unit. We found that differences in summer precipitation and winter minimum temperature, land use intensity, and shrub size may all contribute to the dominance of annual species in the Great Basin, particularly Bromus tectorum. In particular, previous work indicates that summer precipitation and winter temperature drive the distribution of Bromus tectorum in the Great Basin. As a result, sites with wet summers and cold springs, similar to the Chinese sites, would not be expected to be dominated by Bromus tectorum. A history of more intense grazing of the Chinese sites, as described in the literature, also is likely to decrease fire frequency, and decreases litter and shrub dominance, all of which have been demonstrated to be important in Bromus tectorum establishment and ultimate dominance. Further research is necessary to determine if other annuals that follow the same pattern of scarcity in the Junggar Basin and dominance in the Great Basin are responding to the same influences.
\end{abstract}

Keywords: climate; community ecology; convergent evolution; Bromus tectorum; shrub steppe; Junggar Basin; Great Basin

Citation: Wendy TROWBRIDGE, Thomas ALBRIGHT, Scot FERGUSON, Jun LI, Barry PERRYMAN, Robert S NOWAK. 2013. Explaining patterns of species dominance in the shrub steppe systems of the Junggar Basin (China) and Great Basin (USA). Journal of Arid Land, 5(4): 415-427. doi: $10.1007 / \mathrm{s} 40333-013-0174-\mathrm{y}$

Theories about convergent evolution suggest that unrelated organisms subjected to similar selection pressures should share similar physical characteristics
(Cody and Mooney, 1978). For example, the Mediterranean climate regions of California (USA), Chile, South Africa, Australia and the Mediterranean all have

\footnotetext{
*Corresponding author: Wendy TROWBRIDGE (E-mail: wtrowbridge@cabnr.unr.edu)

Received 2012-12-03; revised 2013-03-02; accepted 2013-03-12

(C) Xinjiang Institute of Ecology and Geography, Chinese Academy of Sciences, Science Press and Springer-Verlag Berlin Heidelberg 2013
} 
similar patterns of temperature and precipitation, wet cool winters and hot dry summers, which present a particular set of challenges. In response to these challenges, Mediterranean plant communities have converged on a similar set of physiological mechanisms related to survival and reproduction. In these regions, common plant communities include evergreen sclerophyllous shrubs (Mooney and Dunn, 1969), evergreen forests, drought-deciduous vegetation in the drier areas (Cody and Mooney, 1978) and high plant diversity (Cowling et al., 1996).

The shrub steppes of the Junggar Basin in China and the Great Basin in the western United States also share the same basic climate constraints (Fig. 1). Climate in these regions is classified as Köppen climate type BSk (arid cold steppe), with mean annual temperatures less than $18^{\circ} \mathrm{C}$ and precipitation less than potential evaporation (based on the seasonality of the precipitation; Peel et al., 2007). Although these shrub steppe systems have a broadly similar climate, both regions are topographically diverse and have considerable variation in climate and vegetation conditions. As with Mediterranean flora, cold arid climates of the Junggar Basin and Great Basin constrain the possible vegetation types. These conditions preclude both forests that typically grow in cold regions and xeric cacti that grow in warm arid regions. Shrub and perennial grass dominated communities are able to survive in both cold and arid conditions.

In addition to climate, land use and disturbance influence vegetation communities. Shrub steppe regions in both the Great Basin and Junggar Basin have historically supported grazing based economies. Both regions are also experiencing rapid population growth and changes in historical grazing patterns. However, the chronology, intensity and management of grazing in the two regions differ. The Great Basin was intensely grazed in the early 1900 s, but grazing decreased during the last half century and the first decade of the $21^{\text {st }}$ century (Young and Sparks, 2002). In contrast, the impact from grazing in the Junggar Basin was low in the early $20^{\text {th }}$ century and has significantly increased in the last 50-60 years. Current intensity of grazing differs between the basins for two primary reasons: (1) more regulations that strictly control live- stock numbers occur in the Great Basin, and (2) more sheep, goats, and camels are on rangelands in the Junggar Basin, which consume vegetation more completely than cattle, the primary livestock in the Great Basin. As a secondary impact of grazing regime, the role of fire in the shrub steppe is very different between the two regions: fire has become more frequent, widespread and intense as a result of increased fuel loads in the Great Basin but almost completely absent in the Junggar Basin.

Despite similarities in overall climate and vegetation structure, recent work has shown that certain species function in fundamentally different ways. Specifically, species native to the Junggar Basin behave differently when introduced to the Great Basin. For example, annual species such as cheatgrass (Bromus tectorum) and bur buttercup (Ceratocephala testiculata) are comparatively rare in their home range in the Junggar Basin but dominate local or, in the case of cheatgrass, widespread portions of the landscape when introduced to the Great Basin. Cheatgrass in particular is a highly dominant species in the US. Meinke et al. (2008) found that almost half of the Great Basin $\left(28.1 \times 10^{6} \mathrm{hm}^{2}\right)$ had a moderate to high probability of cheatgrass dominance.

Numerous hypotheses have been proposed to explain the spectacular success of some invasive species, including enemy release (Keane and Crawley, 2002), novel weapons (Callaway and Ridenour, 2004), and biotic resistance (Levine et al., 2004). Clearly, all these factors are important for individual species and are playing a role in the invasions of Great Basin shrub steppe, but the fact that some of these species have been less successful in other grazing regions of the world suggests that individual species characteristics might not be the whole explanation. In addition, successful species invasions have been almost exclusively from Asia to North America. Cheatgrass (Bromus tectorum), bur buttercup (Ceratocephala testiculata), saltlover (Halogeton glomeratus), common Mediterranean grass (Schismus barbatus), bulbous bluegrass (Poa bulbosa), tumble mustard (Sisymbrium altissimum), medusahead (Taeniatherum caput-medusae), and prickly Russian thistle (Salsola tragus) have all been extremely successful invaders in the Western 
United States whereas only buffalobur nightshade (Solanum rostratum) has become locally dominant in the Junggar Basin. Although this asymmetric balance of invasive plants may reflect (at least in part) the asymmetric balance of commerce between the US and China, other factors are likely important (Guo et al., 2006).

Here, we examine the climate, land management, and community ecology of shrub steppe communities of the Central Asian Junggar Basin and the Western North American Great Basin as putative "sister regions". Our hypothesis is that seemingly small differences in climate, community structure and land management may combine to explain differences in species dominance in the two regions. We were particularly interested in one species, Bromus tectorum, that has the potential to form large monotypic stands in the Great Basin but is comparatively rare in the Junggar Basin. To investigate this question, we selected 5 sites in the Great Basin and 5 sites in the Junggar Basin with shrub steppe vegetation, similar climates and similar elevations. We compared the specific community structure of these sites and the overall management history and climate of the two regions using community level vegetation data collected at all 10 sites in the early summer of 2011 and the existing literature.

\section{Methods}

\subsection{Site selection and description}

Although sharing broadly similar climates, the two basins of this study differ in the orientation of mountain ranges and basins, which can influence climate within the basins. The Great Basin in the United States consists of a series of north/south oriented mountain ranges with relatively narrow valleys between ranges. In contrast, the Junggar Basin is one large basin surrounded by very high mountain ranges on the north and south of the basin. Valleys in the Great Basin are higher in elevation than those in the center of the Junggar Basin and have extensive stands of shrub steppe vegetation at lower elevations and across the foothills of the mountain ranges. In contrast, the interior of the Junggar Basin is dominated by sand dunes, and shrub steppe communities are found around the edge of the basin. As a result, sites in the Great Basin follow a rough east-west transect whereas Junggar Basin sites are located in a circular pattern around the edge of the basin (Fig. 1). The sites were selected to

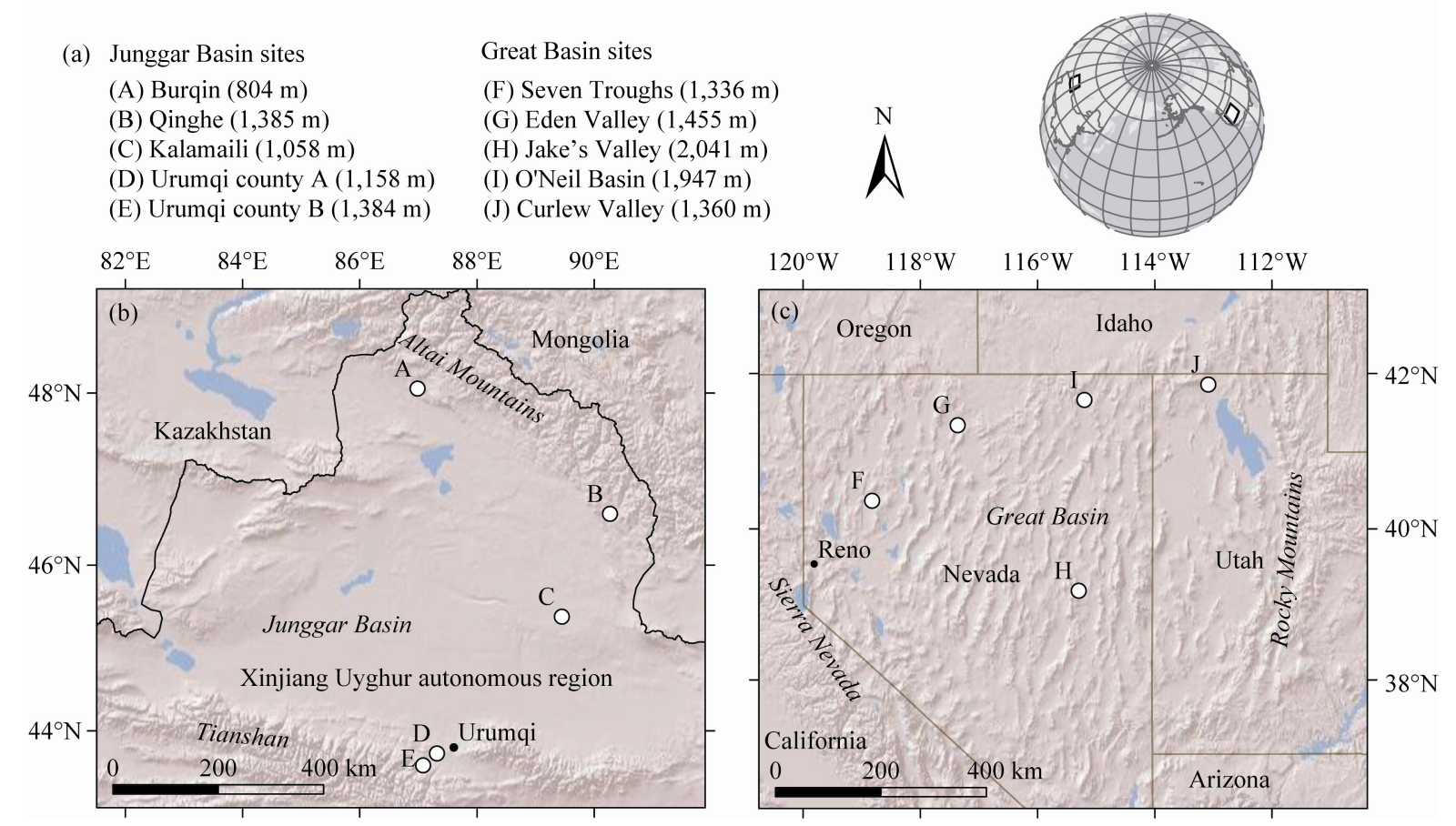

Fig. 1 Map of sites in the Junggar Basin (Xinjiang, China) and the Great Basin (Nevada and Utah, the United States) 
be as floristically similar as possible, specifically excluding the Haloxylon and Tamarix communities in the Junggar Basin and salt flat communities in the Great Basin.

We selected sites within the regions that included shrub steppe vegetation on the lower slopes and foothills of the mountain ranges and avoided extreme environments such as bottomland playas, sand dunes, and salt basins as well as highly disturbed areas. The 5 sites in each basin (Fig. 1) were selected to encompass a similar range of climate and elevation for naturally-occurring shrub steppe vegetation in each basin, with the constraints that sites have similar overall vegetation structure (i.e. shrub steppe) and plant growth forms (i.e. a mixture of shrubs, grasses, and forbs, but no trees).

\subsection{Climate data and analysis}

Owing to their remote locations and low populations, both the Junggar Basin and Great Basin regions are relatively poorly sampled (in space and time) by weather station data. The sparseness of the instrumental record is especially acute in the Central Asia, leading to difficulty in assessing climatic conditions (New et al., 2002; Hijmans et al., 2005). We acquired and processed a spatially-gridded, interpolated weather time series (monthly records) and climatological summary (1961-1990 mean conditions) data set from the Climate Research Unit (New et al., 2002; CRU CL 2.0 and CRU TS3.00; http://www.cru.uea.ac.uk/cru/ data/hrg/). These datasets offer a spatially-rich perspective, with circa $18-\mathrm{km}$ (climate) and $54-\mathrm{km}$ (monthly weather time series) resolution allowing estimation of conditions at points not sampled by the instrumental record. They are subject to modeling uncertainty, especially in areas of extreme topographic relief and sparse samples. However, our sites in the Junggar Basin, where observations are most sparse, are primarily in areas of relatively gentle relief in or near the plains.

\subsection{Field methods}

At each of the 10 sites, four vegetation sampling plots were established. Plots were placed $250 \mathrm{~m}$ apart along the main sampling axis. The main sampling axis was orientated to keep elevation and dominant vegetation relatively constant. Each sampling plot consisted of three 50-m long transects placed $15 \mathrm{~m}$ apart perpendicular to the main sampling axis. Along each transect, plant cover, density, biomass and frequency were measured for each species. Transects and plots within transects provide an estimate of within-site variability, but the sampling unit for the study is the site ( $n=5$ for each basin).

Cover of all species was measured using line point intercept at $1-\mathrm{m}$ intervals along the transect for a total of 600 points per site. A vertical pin was dropped, and the species at all hits were recorded and ground surface cover was categorized as plant, litter (herbaceous or wood), rock, moss, lichen, or soil.

Frequency, density, and biomass of grasses and forbs were measured using circular quadrats placed at $10-\mathrm{m}$ intervals along transects for a total of 60 quadrats per site. The size of the quadrat was scaled to the density of plants and ranged from $0.021 \mathrm{~m}^{2}$ for extremely densely growing plants like cheatgrass to 0.89 $\mathrm{m}^{2}$ for less common species. All species that occurred within the largest plot size were recorded, but for plants occurring at high density subsampling was used to prevent counting thousands of plants. Density and frequency were measured at all quadrat locations. Aboveground biomass was harvested for each species in a subset of two of the five quadrats of each transect, air dried, and weighed. Frequency, density, and biomass of shrubs were measured in two rectangular quadrats parallel to each transect for a total of 24 quadrats per site. The size of shrub quadrats was also scaled to shrub density and ranged from 1.5 to $10 \mathrm{~m}^{2}$. Frequency and density were measured at all shrub quadrats. Volume of the shrubs was measured at one quadrat per transect, and a linear regression was created between volume and biomass by measuring the volume and biomass of 15 representative shrubs of the three most frequent shrub species. This relationship was then used to calculate biomass of shrubs in the quadrats from their volume. In China, all biomass samples were weighed in the field; in the US, samples were weighed in the laboratory. Data on species presence in each plot were used to calculate species richness, diversity, and Simpson's diversity index for each site. Comparisons between functional groups and 
families in the two basins were based on importance values.

Disturbance was qualitatively measured at each plot using five levels of impact ((1) none to slight, (2) slight to moderate, (3) moderate, (4) moderate to extreme, and (5) extreme) for each indicator of disturbance. We recorded five indices of soil disturbance, which included the presence of rills, pedestals and terracettes, gullies, movement or displacement of litter, and soil surface stability. Vegetation decadence and livestock, wildlife, and insect impact were also measured using the qualitative five-level scale. These qualitative assessments were based on guidelines used by the US NRCS to evaluate rangelands (NRCS, 2005). Observations were calibrated with all field personnel at a test site in the Great Basin.

\section{Results}

\subsection{Climate}

We compared climates at our 5 field plot locations in both basins. Although broadly similar, the sites had some key across- and within-region differences. The sites in the Junggar Basin were lower in elevation than those in the United States: $840-1,385 \mathrm{~m}$ as opposed to 1,336-2,040 $\mathrm{m}$ in the Great Basin. The Junggar Basin sites generally have lower annual precipitation, ranging from 172-240 $\mathrm{mm}$ vs. $170-372 \mathrm{~mm}$ in the Great Basin (Figs. 2 and 3). However, the most important distinctions may be how temperature and precipitation vary within the year.

Although average annual temperatures are similar, the Junggar Basin has higher thermal amplitude than the Great Basin with much colder winters and slightly warmer summers. Relative to the Great Basin, the Junggar Basin warms up later in the spring and cools down earlier in the fall, resulting in a shorter growing season. Average monthly temperatures rise above freezing during March in the Great Basin but don't rise above freezing in the Junggar Basin until April. Thaws in February and March are common in the Great Basin and rare in the Junggar Basin. Within the Junggar Basin, our southern sites were generally warmer than northern sites despite their slightly higher elevation. In the Great Basin, the eastern sites were wetter and had more summer precipitation than western sites.

Precipitation is much more concentrated in the summer months in the Junggar Basin than in the Great Basin. Precipitation in the Great Basin is more evenly distributed throughout the year, although a slight gradient of increasing dominance of winter precipitation is apparent in the more western sites. June and July are the wettest months in the Junggar Basin, whereas July is the driest month in the Great Basin (Fig. 3). Although precipitation, usually in the form of snow, is less in the winter at the Junggar Basin sites than at Great basin sites, snow cover is more consistent. Colder and more consistent winter temperatures mean that the ground is often covered by snow all winter in the Junggar Basin. Although the Great Basin receives more snow, warm periods in the winter occur when the snow melts so that snow cover is less consistent.

\subsection{Ecology}

Analysis of vegetation data from plots at the 10 sites indicated important differences in shrub steppe vegetation at the two basins. Although the general vegetation is similar, i.e. shrubs and grasses with a mixture of annual and perennial forbs, details of ground surface cover, plant families, community structure, functional group abundance, and species diversity likely affect the ability of annual species to become established and dominate.

Total plant cover at sites in the Junggar Basin was only $43 \%$, in contrast to $63 \%$ in the Great Basin. Only $17 \%$ of the ground hits in the Junggar Basin were litter; $79 \%$ were soil or rock. The Great Basin had both more litter (34\% of hits) and more plant basal hits (4\%), resulting in only $59 \%$ of ground hits on soil or rock (Fig. 4a).

Despite different evolutionary histories, the same plant families are found in both basins and have similar relative importance. Based on importance value, plant families that are the most common in both basins are the grass family Poaceae and the two most common shrub families, Asteraceae and Chenopodiaceae (Fig. 4b). The Junggar Basin sites had higher cover of shrubs from the Chenopodiaceae, and Great Basin sites had more shrubs from the Asteraceae. Annual 

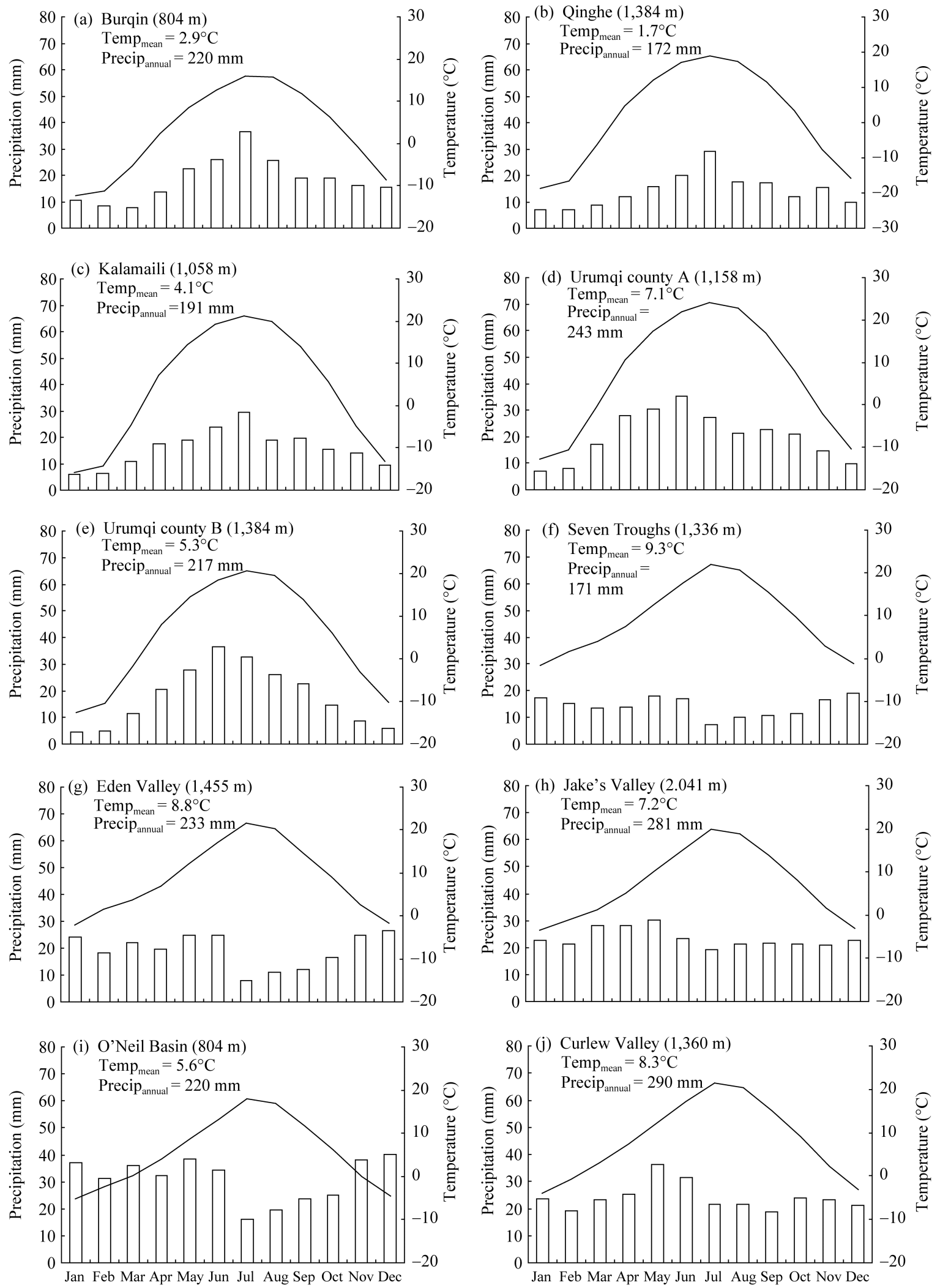

Fig. 2 Climographs of the 10 field sites. The bars and primary axes show precipitation, and the lines and secondary axes show temperature. Site elevations, mean annual temperature, and average total annual precipitation are also indicated. 


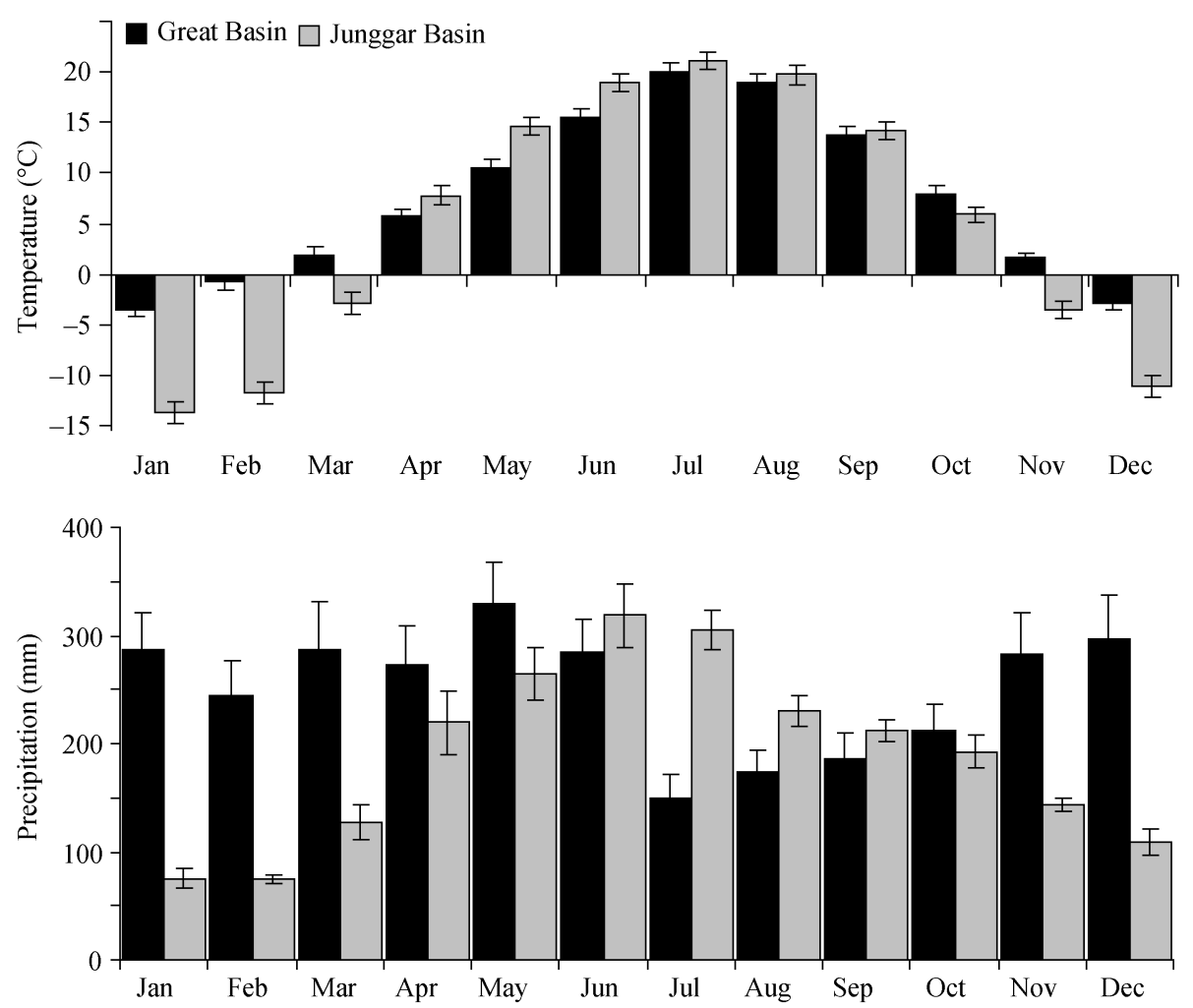

Fig. 3 Mean monthly temperatures (top) and precipitation (bottom) of the five field plot locations in each basin. The error bars indicate variability across sites within each basin.

forbs in the Brassicaceae are common in both basins. Cyperaceae, however, is more common in the Junggar Basin. Some large shrubs in the Rosaceae were found in the Junggar Basin and not in the Great Basin.

Plant community vertical structure differed between the two basins. Layers of vegetation were assessed by the number of times the pin hit multiple different plant species as it was dropped through the vegetation (Fig. $4 c)$. Although one hit was slightly more common in the Great Basin, multiple hits (usually 2 or 3 ) were much more common in the Great Basin, and the Junggar Basin had almost no instances of three hits. Bare ground, soil, or biological crust with no plant canopy layers (no plant cover hits) were much more common in the Junggar Basin. Shrubs in the Great Basin are larger, and more layers of vegetation occur along with a distinct undershrub microhabitat that is either absent or much reduced in the Junggar Basin. Subshrubs with less than $0.001 \mathrm{~m}^{3}$ of canopy volume were common in the Junggar Basin, which restricted the ability of shrubs to develop complex vertical levels of vegetation (Fig. 5).
Although the two basins have the same functional groups, shrubs, subshrubs, grasses and forbs, the abundance of functional groups have important differences between the two basins (Fig. 4d). The most important difference is with the shrubs themselves. In the Great Basin, shrubs are the dominant functional group. They make up $77 \%$ of the biomass and $39 \%$ of the cover. In the shrub steppe areas of the Junggar Basin, subshrubs (woody perennials less than $10 \mathrm{~cm}$ tall) are the dominant functional group. There are large Haloxylon and Tamarix shrubs in the center of the basin, but this is a different plant community. In the shrub steppe, subshrubs make up $52 \%$ of the biomass and $45 \%$ of the cover, whereas shrubs make up only $40 \%$ of the biomass and $12 \%$ of the cover. Figure $4 \mathrm{~d}$ compares importance values of different functional groups.

Overall species diversity was similar in the two basins. Species richness, diversity and Simpson's diversity index were not significantly different between two basins (Fig. 4e). The Junggar Basin had a mean species richness of 33 species per site, and the Great Basin had a mean species richness of 32 per site. Four of 


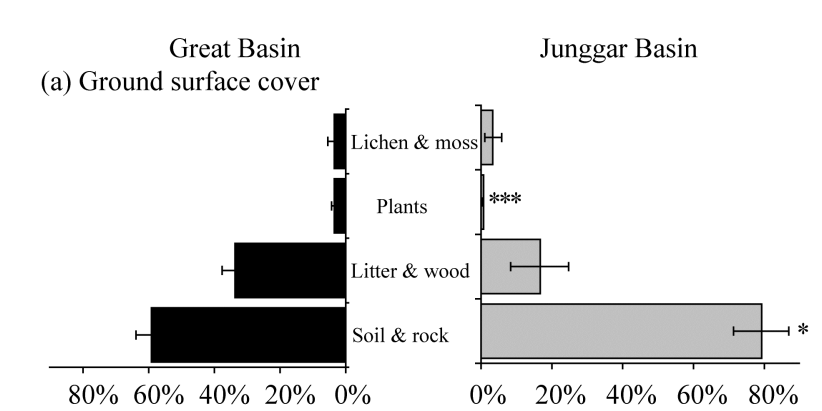

(c) Community structure

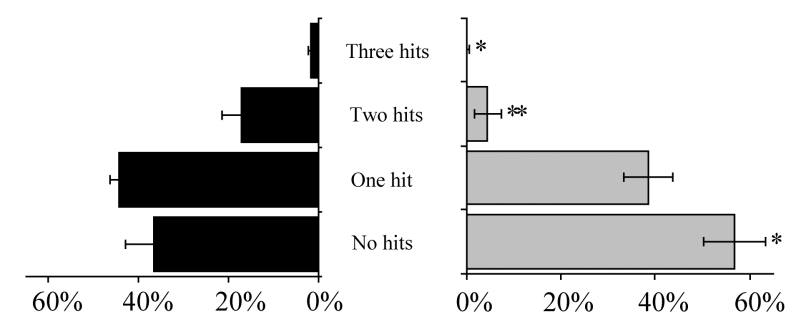

(e) Species richness and Simpson's diversity index

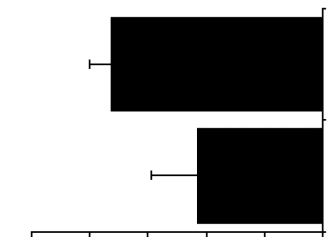

$100 \% 80 \% 60 \% 40 \% 20 \% \quad 0 \%$

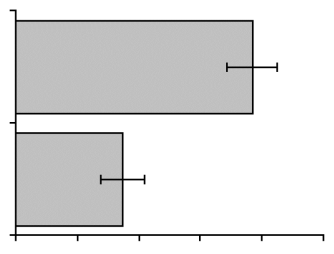

$0 \% \quad 20 \% \quad 40 \% \quad 60 \% \quad 80 \% 100 \%$

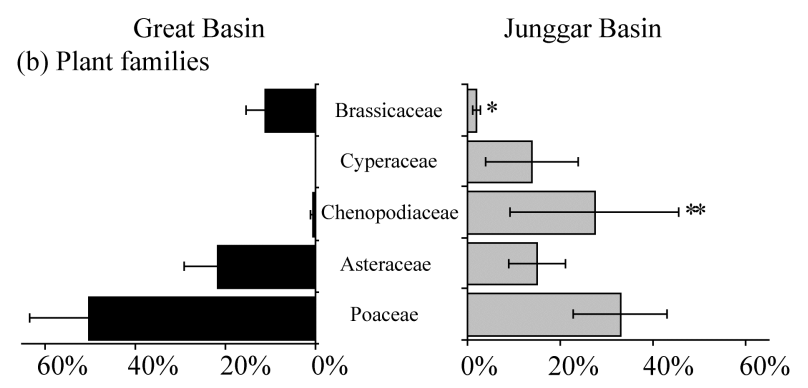

(d) Functional groups

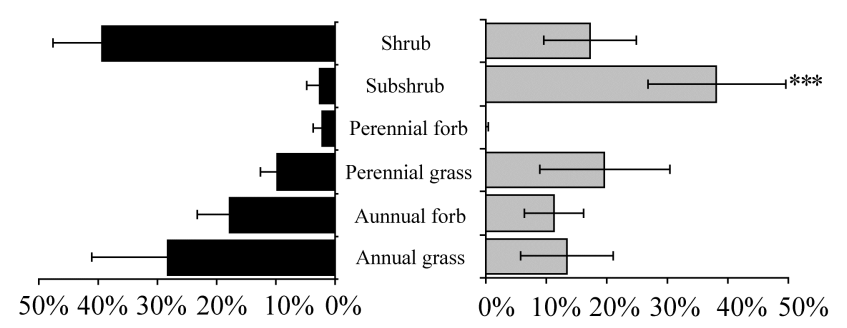

(f) Bromus tectorum

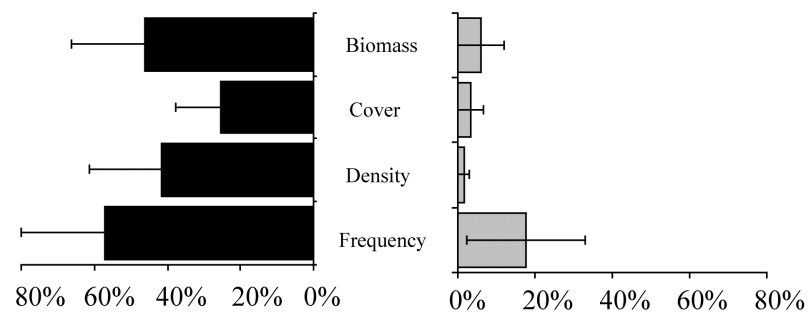

Fig. 4 Comparison of ground surface cover, plant families, community structure, and plant functional groups and diversity between the Great Basin and Junggar Basin. Values shown are means and standard errors of the five plots in each basin. "s indicate the results of Mann Whitney test of significance. * $P=0.1-0.05 ;{ }^{* *}, P=0.05-0.01 ;{ }^{* * *}, P<0.01$.

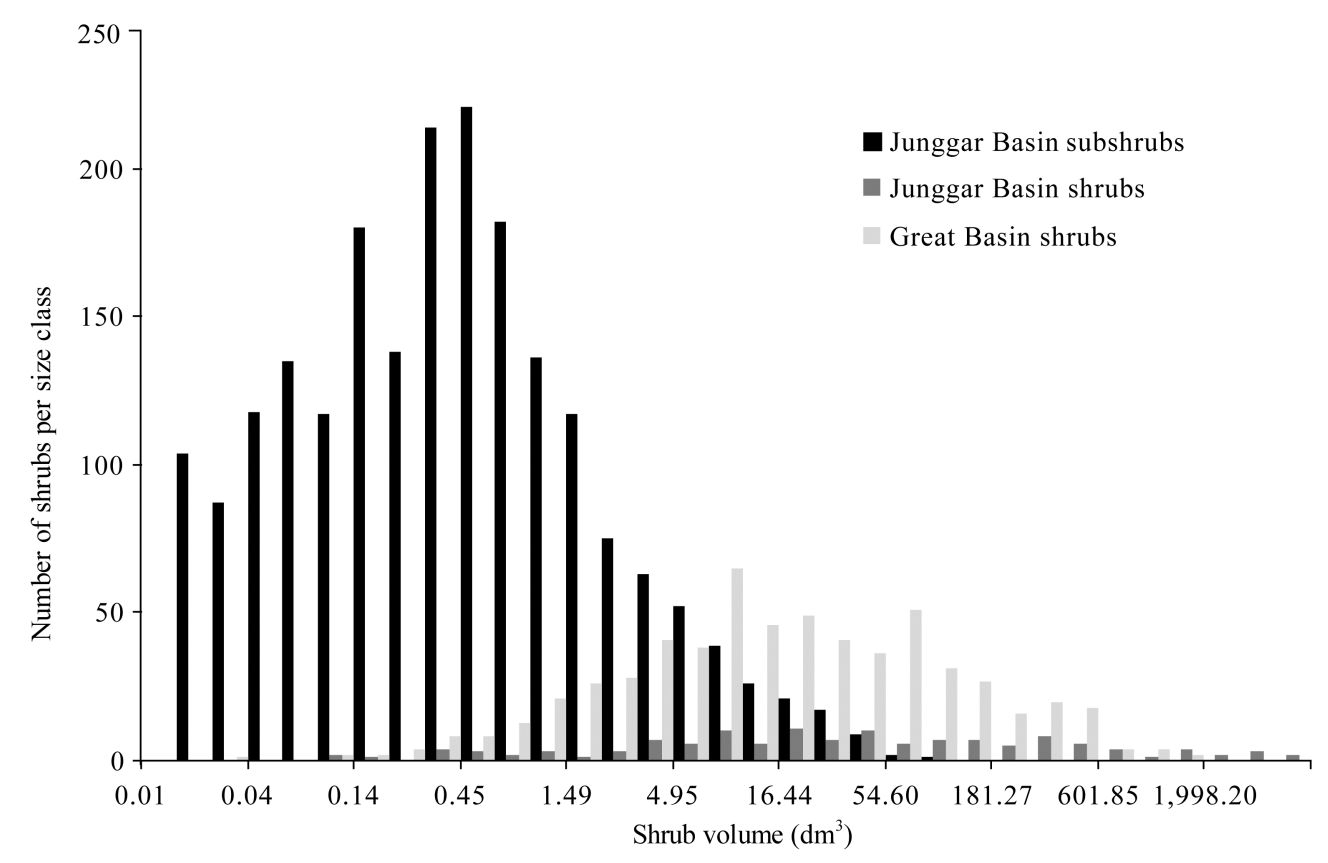

Fig. 5 Histogram of shrub and subshrubs in the two basins 
the sites within the Great Basin were similar in species diversity, but one site in the Great Basin had a higher species diversity than the other Great Basin sites. In the Junggar Basin, one site near Urumqi had significantly lower species diversity than the other Junggar Basin sites.

Bromus tectorum was found in both basins, but it was not found at all locations. Where it was found, frequency, cover, density and biomass were all higher in the Great Basin (Fig. 4f). Density in particular was variable in both basins but much higher densities were observed in the Great Basin. Six of the twenty plots in the Great Basin averaged greater than 2,000 plants $/ \mathrm{m}^{2}$ while the highest plot average density in the Junggar Basin was 392 plants $/ \mathrm{m}^{2}$.

Plot disturbance in the Junggar Basin was characterized by at least slight evidence of grazing by domestic animals ( 5 plots), but moderate levels of grazing were found across all sites (14 plots). Grazing was characterized as moderate to extreme in one plot at one site. Litter movement was characterized as slight at 4 plots, but not present at 16 plots. There was a slight decrease in soil surface stability in 6 plots, and a moderate to extreme decrease in soil stability was noted at one plot. Decreases in soil surface stability often co-occurred with moderate levels of grazing by domestic animals. Presence of rills, plant decadence, and pedestals and terracettes were never noted. Gullies were present at two Junggar sites, but they were infrequent and were found on slopes where precipitation runoff occurred. In the Great Basin, plot disturbance by grazing was characterized most often as none ( 2 plots) or slight (14 plots), and moderate level of grazing was found only at one site. Litter movement was almost always characterized as none (15 plots), but slight litter movement was noted at 5 plots. Soil surface stability, presence of rills, and pedestals and terracettes were similar to the level noted at the Junggar Basin: levels of none to slight were common, and moderate presence of gullies were noted at one plot.

\section{Discussion}

\subsection{Climate}

Mean annual temperature and precipitation are clearly important drivers of broad plant community type. Cold arid conditions in both basins favor shrubs and perennial grasses that can withstand cold temperatures but also have deep roots to allow them to withstand dry conditions. However, seasonal details of climate can also be critical. Work comparing the Karoo in South Africa and the Mojave Desert in the United States shows that winter minimum temperature and the timing of precipitation lead to substantial differences in vegetation structure (Elser and Rundel, 1999). Cowling et al. (2005) found that reliability of rainfall explained the divergence of some plant traits in Mediterranean climate regions. Climate data from the Junggar Basin and Great Basin show similar divergence with more summer rain, more consistent snow cover, and colder winter temperatures in the Junggar Basin.

Bradley (2009) showed that summer rain and winter temperatures were both significant drivers of $\mathrm{Bro}$ mus tectorum distributions in the Great Basin. Specifically, June-September precipitation was the strongest precipitation driver and winter minimum temperature was the strongest temperature driver. Areas with more summer precipitation were less likely to have dense stands of Bromus tectorum. Bradley's study suggests that seemingly minor differences in timing of precipitation and minimum winter temperature alone may be sufficient to describe the observed differences in Bromus tectorum dominance in the two basins and be important drivers for other annual species as well.

Cold winter temperatures leading to more consistent snow cover in the Junggar Basin (Fig. 3) may moderate winter minimum soil temperature (Decker et al., 2003), but it also postpones the growing season for spring annuals. In the Great Basin, annuals that commonly germinate in fall take advantage of warm periods in winter to become established. As a result, by spring they are larger and have deeper roots than annuals in the Junggar Basin. This earlier growth cycle serves to further accentuate differences in growing season length between the two basins.

These observations combined suggest that annual averages of temperature and precipitation exert important constraints that may drive plant distributions. 
Summer rain in particular allows a second flush of annuals to flourish in the Junggar Basin that does not occur in the Great Basin. These summer annuals obviously do not directly compete with spring annuals such as Bromus tectorum.

\subsection{Land use and disturbance}

Some critical differences in land use and grazing pressure may allow some annuals to dominate in the Great Basin whereas they are comparatively rare in the Junggar Basin. Different livestock species impact rangeland differently. Cattle, which are the dominant grazers in the Great Basin, eat more grass. Shrubs such as big sagebrush (Artemisia tridentata) are less palatable to cattle and tend to be more prevalent in shrub steppe areas we studied. In the Junggar Basin, however, the dominant livestock, sheep, goats and camel, feed on both shrubs and grass, and these livestock consume them more completely. This difference in livestock between the two basins may explain the abundance of subshrubs in the Junggar Basin.

The chronology of recent human land use and management differs between the two basins, and these differences help shape current plant communities. In the Junggar Basin prior to 1949, people grazed sheep, goats, camels, horses, and cattle in highland regions, but much of the Xinjiang region was thought to be too arid for large scale grazing (Dahl and McKell, 1986). Since then, policies aimed at increasing development of western regions of China have led to increasing population, grazing, agriculture, and urban land use, especially in the last 20 years (Banks, 1999; Li and Liu, 2009). Grazing rights are not well defined, and individuals are economically encouraged to produce more livestock than is sustainable (Banks, 2001). As individuals are given more autonomy regarding stocking and grazing management, rangeland degradation has increased (Bedunah and Harris, 2002). This degradation is now being recognized (Banks, 2001; Zhao, 2002; Zhao et al., 2005; Han et al., 2008; Dittrich et al., 2010; Liu et al., 2010), and managers in Xinjiang have begun to recognize the fragile nature of vegetation in arid lands (Williams, 1997; Guo et al., 2006) but the magnitude of degradation is uncertain (Ho, 2001; Harris, 2010). Our field observations of litter and community structure and the presence of grazing animals at our sites confirm that they experience intense doses of periodic grazing.

In contrast to the Junggar Basin, European settlement brought large numbers of cattle and sheep to the Great Basin in the late 1800s. A period of intense, season long grazing followed European settlers that continued through the middle of the 1900s. The passage of the Taylor Grazing Act in 1934 announced the beginning of modern grazing management. These regulations were enhanced through the 1980s in order to effectively address concerns about wildlife habitats. The Bureau of Land Management (BLM) now manages $29 \times 10^{6} \mathrm{hm}^{2}$ of federal land in 11 western states. Over the past 40-50 years, stocking levels and extent have decreased dramatically. Recently, introduced plant species have increased in abundance in the Great Basin, replacing native species (Burkhardt and Tisdale, 1976; Mack, 1981; Young et al., 1987). At the time of European arrival, the Great Basin was vegetated mostly with shrubs, with perennial grasses in the productive valley bottoms, and fire was comparatively rare (Vale, 1975a). The vegetation today has lower proportion of perennial grasses and large amounts of exotic annual grasses (Davies et al., 2012).

Fire is almost completely absent in the Junggar Basin but is frequent in the Great Basin and is an important pathway for the establishment of exotic species. The likely mechanism for differences in fire regimes between the two regions is the interaction of greater vegetative cover and biomass, less grazing, and significant presence of highly flammable annual grasses in the Great Basin. We found no evidence of fire in the Junggar Basin, and researchers at the Xinjiang Institute of Ecology and Geography, Chinese Academy of Sciences confirm that fire is so infrequent that the process is completely unimportant for vegetation dynamics. Vegetation structure and biomass in the Junggar Basin are not conducive to fire spread or intensity: the vegetation is more sparse, and litter presence is low. Under current land management, the vegetation structure in the Great Basin, which includes large shrubs, higher biomass, and highly flammable annual grasses, makes it much more vulnerable to wildfires 
(Young and Clements, 2009).

\subsection{Community structure}

Both the Junggar Basin and the Great Basin are arid, cold steppes with substantial shrub steppe communities. Both are dominated by shrubs and perennial grasses and have similar species diversity, and many of the same plant families are found in both regions. However, three main differences in plant communities (shrub size, abundance of litter, and summer annuals) occur and have implications for annual species establishment and eventual dominance.

In the Great Basin, large shrubs create resource islands of increased soil nutrients and moisture and protection from herbivory. These microsites provide establishment sites for both annual and perennial species (Davies et al., 2007). Griffith (2010) found that germination, survival and growth of Bromus tectorum were all greater under shrubs than in shrub interspaces. The much smaller subshrubs in the Junggar Basin are less effective establishment sites and likely create much smaller resource islands. Evans and Young (1972) found that Bromus tectorum seeds have difficulty establishing on a bare seedbed surface. In addition, elevated soil nutrients under large Great Basin shrubs may also allow non-native annuals to outcompete native species (Paschke et al., 2000).

Litter accumulation clearly differs between the two regions, which in turn has implications for species dominance. Litter impacts plant communities through nutrient cycling, soil moisture and creating a physical barrier to seed establishment (Facelli and Pickett, 1991). Work on cheatgrass has shown that increased litter created by annual grasses increases nitrogen availability (Evans et al., 2001; Hooker et al. 2008). In turn, increased nitrogen availability has been shown to favor annuals (Paschke et al., 2000). Litter accumulation also feeds back into the fire cycle. Grazed sites with less litter are less likely to become dominated by cheatgrass even after a fire (Davies et al., 2009). This evidence suggests that litter accumulation contributes to a positive feedback loop by which annual grasses, once established, are more likely to maintain dominance in the Great Basin than the Junggar Basin.

Summer rain in the Junggar Basin leads to a second wave of annual plant growth that does not occur in the Great Basin. Although these annuals do not directly compete with the spring annuals which are so successful in the Great Basin, they do utilize the soil resources. These summer annuals may draw down the shallow nutrient pool that spring annuals rely on in the Junggar Basin and thus reduce the potential for spring annuals to predominate.

\section{Conclusions}

The patterns of species dominance that we describe here have been observed across a variety of systems. Species that are rare in some regions can be dominant in others. When a species becomes dominant outside of its native range, population level explanations are usually put forth (e.g. enemy release, novel weapons). This paper suggests that in some cases, larger scale drivers may also play an important role. Bromus tectorum is considered native to Europe and Asia, but it has been introduced through the world (Upadhyaya et al., 1986). Throughout much of its native and introduced range, it is comparatively rare. In a few areas such as the Great Basin, however, it is dominant. A detailed analysis of the climate of the Great Basin and Central Asia might reveal other locations with suitable summer rainfall and winter minimum temperatures. Study of these regions could allow further insight into the relative importance of climate, land use, and finer scale drivers.

The dominance of Bromus tectorum in the Great Basin also has been attributed to excessive livestock grazing of the past (Jardine and Anderson, 1919; Perryman et al., 2002) and the interaction of wildfire and grazing regime (Knapp, 1998). However, contrary evidence on grazing effects also exists (Courtois et al., 2004), suggesting that Bromus tectorum abundance can be affected both positively and negatively by different grazing systems. Areas in Central Asia with matching climate and different grazing histories may shed light on some of these questions.

The other annual species that follow similar patterns of dominance in the Great Basin and Junggar Basin are less studied. They may respond to similar climatic, land use, and community structure drivers, 
but further work is needed to determine if they respond similarly as Bromus tectorum does.

\section{Acknowledgements}

This project was funded by the US National Science Foundation (1047575) with additional support from the Nevada Agricultural Experiment Station and National Science Foundation Cooperative Agreement (EPS-0814372). We also thank Dr. Elizabeth LEGER for her constructive comments on early versions of this manuscript, Sarah HARDAGE for her assistance with the climate data processing, and the following for their assistance in the filed: Martin MARKEE, Owen BAUGHMAN, Lesley BUNDY, Teresa OLSON, and Erin HOURIHAN from the University of Nevada Reno; Jia WEI, Feng XU, and WenXuan XU from Xinjiang Institute of Ecology and Geography, Chinese Academy of Sciences (XIEG, CAS); and Aysajan ABDUSALAM, Amanulla EMINNIYAZ, Juan QIU, and Tao YE from Xinjiang Agricultural University (XAU). This research would not have been possible without the vision and leadership of WenJiang LIU (XIEG, CAS) and the detailed vegetation ecology knowledge of YuanMing ZHANG (XIEG, CAS), WeiKang YANG (XIEG, CAS) and DunYan TAN (XAU).

\section{References}

Banks T J. 1999. State, community, and common property in Xinjiang: synergy or strife? Development Policy Review, 17(3): 293-313.

Banks T J. 2001. Property rights and the environment in pastoral China: evidence from the field. Development and Change, 32(4): 717-740.

Bedunah D J, Harris R B. 2002. Past, present and future: rangelands in China. Rangelands, 24(4): 17-22.

Bradley B A. 2009. Regional analysis of the impacts of climate change on cheatgrass invasion shows potential risk and opportunity. Global Change Biology, 15(1):196-208.

Burkhardt J W, Tisdale E W. 1976. Causes of juniper invasion in southwestern Idaho. Ecology, 57(3): 472-484.

Callaway R M, Ridenour W M. 2004. Novel weapons: invasive success and the evolution of increased competitive ability. Frontiers in Ecology and the Environment, 2(8): 436-443.

Cody M L, Mooney H A. 1978. Convergence versus non-convergence in Mediterranean-climate ecosystems. Annual Review of Ecology and Systematics, 9: 265-321.

Courtois D R, Perryman B L, Hussein H S. 2004. Vegetation change after 65 years of grazing and grazing exclusion. Journal of Range Management, 57: 574-582.

Cowling R M, Rundel P W, Lamont B B, et al. 1996. Plant diversity in Mediterranean-climate regions. Trends in Ecology \& Evolution, 11(9): 362-366.

Cowling R M, Ojeda F, Lamont B B, et al. 2005. Rainfall reliability, a neglected factor in explaining convergence and divergence of plant traits in fire-prone mediterranean-climate ecosystems. Global Ecology and Biogeography, 14(6): 509-519.

Dahl B E, McKell C M. 1986. Use and abuse of China's deserts and rangelands. Rangelands, 8(6): 67-271.

Daubenmire R. 1985. The western limits of the range of the American Bison. Ecology, 66(2): 622-624.

Davies G M, Bakker J D, Dettweiler-Robinson E, et al. 2012. Trajectories of change in sagebrush steppe vegetation communities in relation to multiple wildfires. Ecological Applications, 22(5): $1562-1577$.

Davies K W, Bates J D, Miller R F. 2007. The influence of Artemisia tridentata ssp. wyomingensis on microsite and herbaceous vegetation heterogeneity. Journal of Arid Environments, 69(3): 441-457.

Davies K W, Svejcar T J, Bates J D. 2009. Interaction of historical and nonhistorical disturbances maintains native plant communities. Ecological Applications, 19(6): 1536-1545.

Decker K L M, Wang D, Waite C, et al. 2003. Snow removal and ambient air temperature effects on forest soil temperatures in Northern Vermont. Soil Science Society of America Journal, 67(4): 1234-1242.

Dittrich A, Buerkert A, Brinkmann K. 2010. Assessment of land use and land cover changes during the last 50 years in oases and surrounding rangelands of Xinjiang, NW China. Journal of Agriculture and Rural Development in the Tropics and Subtropics, 111(2): 129-142.

Esler K J, Rundel P W. 1999. Comparative patterns of phenology and growth form diversity in two winter rainfall deserts: the succulent Karoo and Mojave Desert ecosystems. Plant Ecology, 142(1-2): 97-104.

Evans R, Young J. 1972. Microsite requirements for establishment of annual rangeland weeds. Weed Science, 20: 350-356.

Evans R D, Rimer R, Sperry L, et al. 2001. Exotic plant invasion alters nitrogen dynamics in an arid grassland. Ecological Applications, 11(5): 1301-1310.

Facelli J M, Pickett S T A. 1991. Indirect effects of litter on woody seedlings subject to herb competition. Oikos, 62(2): 129-138.

Griffith A B. 2010. Positive effects of native shrubs on Bromus tectorum demography. Ecology, 91(1): 141-154.

Guo Q F, Qian H, Ricklefs R E, et al. 2006. Distributions of exotic plants in eastern Asia and North America. Ecology Letters, 9(7): 827-834.

Guo Z G, Liang T G, Liu X Y, et al. 2006. A new approach to grassland management for the arid Altai region in Northern China. The Rangeland Journal, 28(2): 97-104.

Haines F D. 1940. The Western limits of the buffalo range. Pacific Northwest Quarterly, 31(4): 389-398.

Han J G, Zhang Y J, Wang C J, et al. 2008. Rangeland degradation and restoration management in China. The Rangeland Journal, 30(2): 233-239. 
Harris R B. 2010. Rangeland degradation on the Qinghai-Tibetan plateau: a review of the evidence of its magnitude and causes. Journal of Arid Environments, 74(1): 1-12.

Hijmans R J, Cameron S E, Parra J L, et al. 2005. Very high resolution interpolated climate surfaces for global land areas. International Journal of Climatology, 25(15): 1965-1978.

Ho P. 2001. Rangeland degradation in north China revisited? A preliminary statistical analysis to validate non-equilibrium range ecology. Journal of Development Studies, 37(3): 99-133.

Hooker T, Stark J, Norton U, et al. 2008. Distribution of ecosystem C and $\mathrm{N}$ within contrasting vegetation types in a semiarid rangeland in the Great Basin, USA. Biogeochemistry, 90(3): 291-308.

Jardine J T, Anderson M. 1919. Range Management on the National Forest. Washington: United States Department of Agriculture, 98.

Keane R M, Crawley M J. 2002. Exotic plant invasions and the enemy release hypothesis. Trends in Ecology \& Evolution, 17(4): 164-170.

Knapp P A. 1998. Spatio-temporal patterns of large grassland fires in the intermountain west, USA. Global Ecology \& Biogeography Letters, 7: 259-272.

Levine J M, Adler P B, Yelenik S G. 2004. A meta-analysis of biotic resistance to exotic plant invasions. Ecology Letters, 7(10): 975-989.

Li Y C, Liu C X. 2009. Driving forces of the changes of land use/cover in northern China: 1987-2006. Arid Land Geography, 32(1): 37-46.

Liu J Y, Zhang Z X, Xu X L, et al. 2010. Spatial patterns and driving forces of land use change in China during the early $21^{\text {st }}$ century. Journal of Geographical Sciences, 20(4): 483-494.

Mack R N. 1981. Invasion of Bromus tectorum L into Western North-America-an ecological chronicle. Agro-Ecosystems, 7(2): $145-165$.

Mack R N, Thompson J N. 1982. Evolution in steppe with few large, hoofed mammals. American Naturalist, 119(6): 757-773.

Meinke C W, Knick S T, Pyke D A. 2009. A spatial model to prioritize sagebrush landscapes in the intermountain west (USA) for restoration. Restoration Ecology, 17(5): 652-659.

Mooney H A, Dunn E L. 1970. Convergent evolution of Mediterranean-climate evergreen sclerophyll shrubs. Evolution, 24(2): 292-303.

Natural Resources Conservation Service. 2005. Interpreting Indicators of Rangeland Health. Technical Reference, 1734-6. Denver: BLM National Business Center.

New M, Lister D, Hulme M, et al. 2002. A high-resolution data set of surface climate over global land areas. Climate Research, 21(1): $1-25$.

Paschke M W, McLendon T, Redente E F. 2000. Nitrogen availability and old-field succession in a shortgrass steppe. Ecosystems, 3(2): 144-158.

Peel M C, Finlayson B L, McMahon T A. 2007. Updated world map of the Koppen-Geiger climate classification. Hydrology and Earth System Sciences, 11(5): 1633-1644.

Perryman B L, Olson R A, Petersburg S, et al. 2002. Vegetation response to prescribed fire in Dinosaur National Monument. Western North American Naturalist, 62: 414-422.

Sperry L J, Belnap J, Evans R D. 2006. Bromus tectorum invasion alters nitrogen dynamics in an undisturbed arid grassland ecosystem. Ecology, 87(3): 603-615.

Tueller P T. 1989. Vegetation and land use in Nevada. Rangelands, 11(5): 204-210.

Upadhyaya M K, Turkington R, McIlvride D. 1986. The biology of Canadian weeds. 75. Bromus-Tectorum L. Canadian Journal of Plant Science, 66(3): 689-709.

Vale T R. 1975a. Presettlement vegetation in sagebrush-grass area of intermountain west. Journal of Range Management, 28(1): 32-36.

Vale T R. 1975b. Report by bureau of land management on range conditions and grazing in Nevada. Biological Conservation, 8: 257-260.

Williams D M. 1997. The desert discourse of modern China. Modern China, 23(3): 328-355.

Young J, Clements C. 2009. Cheatgrass: Fire and Forage on the Range. Reno: University of Nevada Press, 348.

Young J A, Evans R A, Kay B L. 1987. Cheatgrass. Rangelands, 9(6): 266-270.

Young J A, Sparks B A. 2002. Cattle in the Cold Desert. Reno: University of Nevada Press, 336.

Zhao H L, Zhao X Y, Zhou R L, et al. 2005. Desertification processes due to heavy grazing in sandy grassland, Inner Mongolia. Journal of Arid Environments, 62(2): 309-319.

Zhao W Y. 2002. Deterioration, causes and control strategies of grassland resources in Xinjiang, China. Pratacultural Science, 19(2): 19-22. 